\title{
Deconstructing robotic lobectomy
}

\author{
Inderpal S. Sarkaria, MD, FACS
}

\author{
From the Department of Cardiothoracic Surgery, University of Pittsburgh School of Medicine and University of \\ Pittsburgh Medical Center, Pittsburgh, Pa. \\ Disclosures: Author has nothing to disclose with regard to commercial support. \\ Received for publication July 7, 2016; accepted for publication July 12, 2016. \\ Address for reprints: Inderpal S. Sarkaria, MD, FACS, Department of Cardiothoracic Surgery, University of \\ Pittsburgh Medical Center, UPMC Presbyterian-Shadyside, 5200 Centre Ave, Suite 715.27, Pittsburgh, \\ PA 15232 (E-mail: sarkariais@upmc.edu). \\ J Thorac Cardiovasc Surg 2016;152:998 \\ $0022-5223 / \$ 36.00$

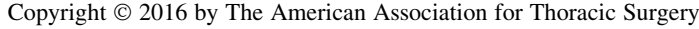 \\ http://dx.doi.org/10.1016/j.jtcvs.2016.07.020
}

The landscape of cardiothoracic surgical training has changed significantly in response to several factors. These include a health care environment with physicians held increasingly accountable to metric-driven patient outcomes, surgical trainee work hour restrictions, a widening array of technically complex approaches to traditional operations, and a fast-paced evolution of sophisticated (but not necessarily proven) surgical technologies, including robotics. It is not surprising that in a survey of recent graduates of thoracic residency programs, the majority of respondents reported that they needed more instruction or lacked confidence in an array of advanced minimally invasive operations, including robotic pulmonary resections. ${ }^{1}$ Although this finding is open to significant differences in interpretation, it nevertheless identifies a self-stated desire on the part of trainees to obtain greater competency in advanced robotic cardiothoracic operations during their training and a parallel opportunity for surgical educators to fill these gaps in training (whether true, believed, or perceived).

Accordingly, in their study in this issue of the Journal, Cerfolio and colleagues ${ }^{2}$ introduce a method of teaching robotic lobectomy involving division of the operation into 19 technical components, each providing a discrete skill-learning opportunity. Cerfolio and colleagues ${ }^{2}$ suggest this paradigm allows graded teaching of the operation while maintaining excellent surgical outcomes, including "optimal" surgical operative times. As the authors themselves admit, the study has significant limitations and suffers from a study design and methodology that is often vague and difficult to follow, as well as conclusions that are based on unconvincing associations between training methodology and patient outcomes that cannot be distinguished from the impact of the attending surgeon's learning curve and acquired expertise during the coinciding period of the study. It is also debatable whether time performing a task is an appropriate primary metric by which to judge

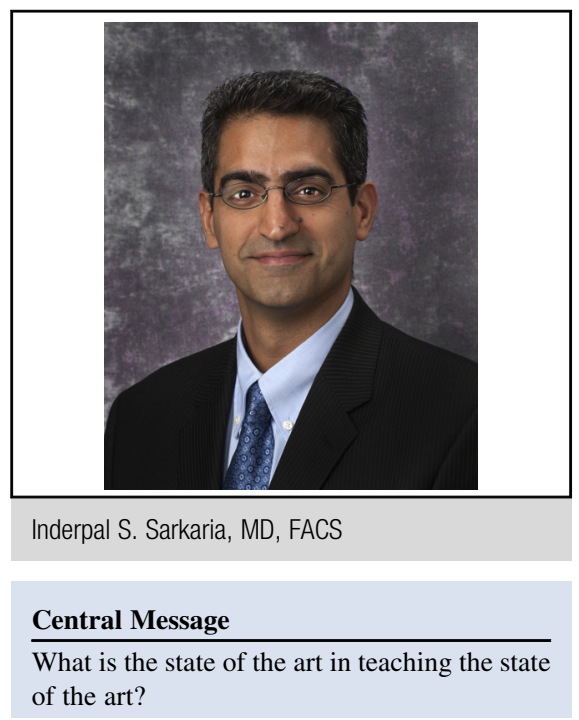

See Article page 991.

the trainee's success. Although "time" is an important component, should not the primary focus be on "quality" of the trainee's work?

In my opinion, however, these limitations are of little consequence compared with the central message and seminal worth of this study, which represents a substantial, laudable, and widely applicable potential methodology to create graded, component-based pathways to surgical competency in complex procedures. It is arguable that the limitations of the study speak more to a common wisdom that certain aspects of surgical education remain an art to a greater or lesser extent, not easily amenable to our efforts to discretely compartmentalize and quantify the process. Although further methodologic refinement and study are warranted to corroborate the current findings, Cerfolio and colleagues ${ }^{2}$ have laid a sound foundation on which further to build, explore, and potentially improve the science and art of teaching complex operations to our surgical trainees.

\section{References}

1. Chu D, Vaporciyan AA, Iannettoni MD, Ikonomidis JS, Odell DD, Shemin RJ, et al. Are there gaps in current thoracic surgery residency training programs? Ann Thorac Surg. 2016;101:2350-5.

2. Cerfolio RJ, Cichos KH, Wei B, Minnich DJ. Robotic lobectomy can be taught while maintaining quality patient outcomes. J Thorac Cardiovasc Surg. 2016; 152:991-7. 